Joanna Wasiluk

DOI $10.15290 /$ sw.2019.19.28

Uniwersytet Warszawski

Wydział Lingwistyki Stosowanej

Katedra Rusycystyki

tel.: +48 696238719

e-mail: j.wasiluk@uw.edu.pl

ORCID ID: https://orcid.org/0000-0002-8994-8177

\title{
Духовно-нравственные ценности в структуре Российских медиатекстов (на примере газеты Известия)
}

Ключевые слова: духовно-нравственные ценности, глобализация, кризис ценностей, средства массовой информации, общество

Духовно-нравственные ценности, согласно Большому психологическому словарю - это установки личности, являющиеся системообразующим элементом ценностных ориентаций, указывающие на их культурное, социальное, человеческое значение, регулирующие сознательную деятельность и поведение, придающие им нравственный характер и ориентирующие ее на достижение высших идеалов [БПС 2007,63]. Притом следует иметь в виду, что традиционные духовно-нравственные ценности - «это ценности устойчивые, переходящие из одного поколения к другому, унаследованные от предшествующих поколений, имеющие вневременной характер и мироохранительные по своему существу» [Дьячкова 2007, 141]. Так как традиционные общечеловеческие ценности выражены в божественных заповедях разных религий они и приобрели характер общенациональных и общечеловеческих ценностей.

Однако развитие цивилизации и связанные с ним преобразования, происходящие в обществе, сказываются на системе духовно-нравственных ценностей. Как подчеркивают исследователи, появляются новые ценности, возникшие под влиянием новых обстоятельств, обогащают- 
ся ранее сложившиеся, формируются современные духовно-нравственные ценности, которые являются результатом сочетания традиционных и новых ценностей [Дьячкова 2007, 147-148]. Цивилизация, как отмечает Т. П. Никитина, ставит перед индивидом две взаимоисключающиеся задачи, с одной стороны, масс-медиа, проникая в каждый дом и закуток культуры, требуют от индивида «быть собой» «обрести себя», требуют исключительности. С другой же стороны, индивид сталкивается с совсем другим, противоречащим требованием культуры - «будь правильным» [Никитина 2012, 114-115].

Следовательно, в последние годы духовно-нравственные ценности заметно начали изменятся, чему причиной стремительные изменения в мире конца XX - начала XXI века, связанные с глобализацией. Именно они вызвали кризисные явления как в социально-экономической, так и духовной сфере жизни общества. В России, на фоне заметно возрастающего кризиса духовно-нравственных ценностей в документе Стратегии развития воспитания в Российской Федерации на период до 2025 года, подписанным Председателем Правительства РФ Дмитрием Медведевым был утвержден даже их список, согласно которому к системе духовно-нравственных ценностей, сложившихся в процессе культурного развития России, принадлежат: человеколюбие, справедливость, честь, совесть, воля, личное достоинство, вера в добро, стремление к исполнению нравственного долга перед самим собой, своей семьей и своим Отечеством ${ }^{1}$.

По мнению исследователей духовный кризис проявляется «в резком падении духовного здоровья, в смене идеологических ориентиров и появлении духовного вакуума, в переоценке и переосмыслении ценностей, деструктивности складывающихся ценностных установок [...], нарушении норм межличностных отношений» [Дьячкова 2007, 141] . Существенную роль здесь отыгрывают СМИ. Основная угроза духовной безопасности усматривается именно с их стороны, так как они осознанно манипулируют общественным сознанием. Во многом это связано со стремлением СМИ стать как можно более эффективным и привлечь внимание как можно большей аудитории, где эффективность воспринимается как «степень достижения журналистских целей, соответствующих потребностям общества в массовой информации, с учетом реальных возможностей, как ее производителей, так и потребителей» [Прохоров 1988, 251].

1 Материалы взяты с сайта: http://www.pravmir.ru/v-rossii-utverzhden-spisok-duho vno-nravstvennyih-tsennostey/, доступ: 14.08.2017. 
По сути, реципиент рассчитывает получить объективную информацию в СМИ, забывая о том, что ее отбирают и преподносят люди, которые вовсе не думают о том, чтобы представить объективную реальность а лишь мнение о ней. Индивидуальное мнение воспринимается, по словам Т. П. Никитиной, «как что-то внешнее, что должно быть сформировано «объективной» информацией, где место объективности уступает всеобщность информации» [Никитина 2012, 116]. Это, в свою очередь, способствует манипуляции сознанием, «так как теряется различие между собственным мнением и способом подачи информации, а также оценкой событий, представленных в СМИ» [Там же].

Как подчеркивается, «зло в информационном обществе выражается в нарушении иерархии, которая имеет негативные последствия как в духовной, так и физической сфере. Ценности в информационном поле утверждаются не рефлексией индивида, а своей распространенностью. Но, во-первых, зачастую распространенными оказываются гедонистические ценности в своем примитивном виде [...], а во-вторых, навязанные ценности лишаются жизненного разнообразия, что делает их одномерными, будто заученными, а не прожитыми, что приводит к утрате нравственного поведения и переходу к легальному. [...] в современном обществе формулируется принцип «не среда для человека, а человек для среды». Человек превращается в средство утверждения массовой культуры. [...] СМИ вместо того, чтобы освещать реальность, превращаются в сверхреальность, дезориентируя тем самым индивида» [Там же].

Следовательно, СМИ отыгрывают огромную роль в процессе продвижения ценностей, так как журналисты довольно часто упоминают про ценности связанные с культурой, моралью и нравственностью. Однако во многом эти упоминания имеют манипулятивный характер, поскольку «СМИ тиражируют образцы и модели поведения людей, которые в дальнейшем в сознании человека начинают выступать ориентиром для их жизни и деятельности» [Тучкова 2012, 160]. Следовательно, информационный контент, формируемый СМИ, определяет вкусы и пристрастия аудитории. Как отмечают исследователи, СМИ могут преувеличивать роль одних событий и умалчивать о других, кроме того они дают определения явлениям, попавшим в их фокус, сопровождая информацию своими собственными комментариями и оценками [Там же].

В нашем анализе, основанном на изучении содержания 200 новостных сообщений и статей, взятых из электронной версии газеты «Изве- 
стия» 2 за период с 2013 по 2017, попытаемся определить, используя качественный и количественный метод, специфику используемых в тексте духовно-нравственных ценностей, учитывая при этом контекст, в котором они выступают. Как нам кажется, духовно-нравственные ценности являются немаловажными вопросами в жизни любого общества.

Учитывая, что фундаментальными духовно-нравственными ценностям, которые служат идеалом для большинства людей, являются истина, доброта, справедливость, свобода, любовь и милосердие, мы решили сосредоточить наше внимание именно на их употреблении. Как оказалось в новостных сообщениях чаще всего использовались такие ценности как истина, доброта и справедливость. Истина, как правило выступает во фразеологических сочетаниях, а также в сочетаниях со словами простая и абсолютная, а также в сочетании с временными отрезками, ср. 1) Истина где-то посередине, (31.08.2017); 2) Каждый чиновник должен запомнить и уяснить одну простую истину: единственным иивилизованньм способом разрешения конфликтов со СМИ может бъть только суд, (02.11.2016); 3) Но правда состоит в том, что без эффективно работаюших элементов невозможна и их эффективная координация - это абсолютная истина, (22.20.2016); 4) Но рано или поздно Москва встанет. Вот тогда и наступит «момент истинь»». Вот тогда и придет время принимать трудные решения (про решение транспортной проблемы в городе Москве - И. В.), (02.10.2013); 5) Теперь наступает час истинь, когда Европа коренным образом меняет свое отношение к ливийским политическим силам. Надеюсь, ее примеру последуют и США, (18.04.2017).

Что интересно, значительно чаще выступает слово истина в форме имени прилагательного истинныи,, подчеркивая, таким образом, важность того объекта, к которому относится, ср. 1) По иниииативе России мьи поговорим о роли истинной демократии в современном мире уже в октябре на 13\%-й Ассамблее МПС, которая пройдет в Петербурге, (13.10.2017); 2) Спасибо Дональду за честность. Политолог Вероника Крашенинникова об истинном лице Трампа и последствиях его раскрытия для мира и России, (21.08.2017); 3) Так что и тут Навальный показал свое, что называется, истинное лиио, (12.06.2017); 4) У новой Гетманщинь новая идеология - это уже не война христиан с мусульманами, а война «истинньх европейиев» с русскими, (24.08.2017); 5) Красота истинной леди должна

\footnotetext{
2 Официальный сайт газеты «Известия»: http://izvestia.ru/.
} 
быть естественной - так гласит этикет и запрещает нам все «протезы»: накачаннье губь, накладнье волосьи, ресницьи, ногти, даже гель-лак, (19.08.2017); 6) Меня смущает только одно: современные девушки с головой уходят в работу, идут вверх по карьерной лестниче, забывая о своем истинном предназначении, (07.08.2017); 7) Вместе с тем в Москве считают, что истинные иели Вашингтона находятся совершенно в иной плоскости, (14.11.2016); 8) Специально для тех, кто продолжает сомневаться в истинных намерени$\boldsymbol{я \boldsymbol { x }}$ России, в Кремле вновь подчеркнули, что противостояние с кем бъл то ни билло «нам не нужно», (05.10.2016); 9) У которой (американской стороны - И. В.) (как, впрочем, и у всего остального мира) после ньнешнего послания не может быть никаких сомнений относительно истинньх целей и приоритетов нашей международной политики, (02.10.2016).

Анализируя контексты, в которых используется слово доброта, их можно разделить на три вида. Во-первых, это контексты, в которых доброта воспринимается как ценность, являющаяся составляющей культуры, а также как человеческая ценность, к которой следует стремиться, ср. 1) Mьл уже привькли восхищаться самоотверженныли людьми, отваживиимися посвятить себя чужим детям, верим в человеческую доброту, (23.05.2017); 2) И если отеи Дмитрий смотрел на Познера так, «что если взглядыл могли бь убивать, я был бы трупом. Он показался мне человеком бесчестным, высокомернылм и лишенным христианской доброты, терпеливости и всепрощения», то разговор с Кантором остался для Познера вкусньл ужином с невкусным послевкусием, (06.02.2015); 3) На первом месте у жителей России остаются такие качества, как воля, амбииии, доброта и порядочность. Именно они помогают добиться более вьсокого положения в обществе, (20.10.2016); 4) И будете доброжелательны и миролюбивы. Потому что миролюбие и доброта - это ведь тоже составляющие культуры. Внутренней культуры человека, (16.10.2016); 5) Пусть в этом монументе (монумент воссоединения с Крымом - И. В.) отразятся боль и доброта, наша великая культура и непобедимое оружие, (14.10.2016); 6) Причина успеха картинь в военнье годы проста: востребованными в первую очередь оказались оптимизм, высокая иенность искренних чувств, доброта и красота наших героев, (22.06.2016); 7) И здесь важную роль могут сыграть уроки понимания инвалидности или уроки добротьл. Два года назад мы с коллегами по Общественной палате России начали проект по внедрению таких уроков в российских школах, (01.12.2016). 
Здесь хотелось бы отметить, что последний пример является истинным доказательством кризиса духовно-нравственных ценностей, учитывая необходимость введения такого рода уроков в школы.

Во-вторых, это контексты, в которых доброта противопоставляется отрицательным качествам, таким как напр. ненависть, зависть, жестокость, ср. 1) Теперешние фильмь - другие. Они жестокие, недобрые. Поэтому я по-прежнему люблю наши старье мультики, сделанные в лучиие годы «Союзмультфильма». Именно потому они так трогают душу, что сделань с юмором и добротой. Это самое главное, (01.09.2015); 2) Ведь сказка «Аленький чветочек» - это огромная мистическая метафора. Когда уродливое, темное, свирепое с виду побеждается любовью, добротой, красотой и лаской. Не эта ли сказка является символом сегодняшнего мира, где все расчеловечено и человеческое должно опять вернуться в нашу жизнь?, (06.07.2015); 3) Совсем не из доброты приняла к себе в Лондон Великобритания рекордное количество российских олигархов - и отпушенных Россией, и сбежавших из России, - но из веками культивируемой, уже наследственной ненависти к нашей стране, (22.01.2016); 4) Откуда берется эта самая русофобия? Да все оттуда же - из зависти. Только завидуют не материальному благополучию, а душевнылм качествам - доброте, справедливости, готовности прийти на помощь, поделиться последним, не дрогнуть при любых обстоятельствах, (16.12.2015); 5) «Обама заявил, что "Россия пьттается восстановить былую славу силой". Зато США с их войнами и военньми расходами славны в мире только добротой», - написал Пушков (председатель комитета Госдумы по международным делам - И. В.), (21.09.2016).

В-третьих, доброта довольно часто встречается в цитатах из выступлений президента В. В. Путина, который в своих высказываниях, зачастую, ссылается на духовно-нравственные ценности, что является, от части, одним из методов формирования образа, имиджа политика, в данном случае образа президента, cр. 1) Человека оченивают по поступкам и порядочности, каждый выбирает, как поступить, - заявия президент, в очередной раз напомнив юным дарованиям, что главное - это честь, смелость, взаимоуважение, доброта и патриотизм, который в России передается от поколения $\kappa$ поколению, (01.09.2015); 2) Так что психотерапевтическую задачу для всей страны прямая линия выполнила. Гениальный, конечно, был ответ на вопрос: «Вам не кажется, что ваши друзья пользуются вашей добротой?». «Почему только друзья, - ответил президент. Все пользуются», (16.04.2015). 
Относительно использования слова справедливость, в качестве духовно-нравственной ценности, следует отметить, что рядом с контекстами, подчеркивающими ее существенность для жизни общества, приведенными ниже, ср. 1) Времена изменились, и нет уже ни СССР, ни сочлагеря. Однако запрос на справедливость, запрос на сочиальное равенство и гарантированные права всех людей на земле никуда не делись. [...] И первыми этот запрос предъявляют именно молодье. Это иногда называют усилением левачких настроений, но это не так: не коммунизма, а новой справедливости хотят молодые, (17.10.2017); 2) Поскольку справедливостью не торгуют, отторжение будет вызыьвать любая идея «выкупа» Крыма посредством тех или иньх компенсачий Украине. Но в идеале россиянам хотелось бы, чтобь решение крымского вопроса перестало вызьивать международные споры. Поэтому для них важно, чтобы восстановление исторической справедливости нашло, наконеи, международную поддержку, (19.10.2017); 3) Именно Россия продемонстрировала миру непревзойденные образцы духовного подвижничества, напряженнейшие мистерии борьбы «правды» и «кривды», обостренное чувство справедливости, $(03.10 .2017)$, 4) Но образование должно еще производить справедливость. В наиболее развитых странах образование сегодня не просто обеспечивает равныии старт - оно работает как механизм «сочиального перемешивания», (15.08.2017); довольно популярным стало использование сочетания сочиальная справедливость, которое авторами сообщений и статей толкуется по-разному, что некоторые из них и сами подчеркивают, ср. 1) Сама же резолючия по акиизам на следуюший год автоматически актуализирует вопрос по отмене транспортного налога. Поиск сочиальной справедливости в этом контексте должен быть продолжен, особенно если учесть предстоящий выборный год, (22.09.2017); 2) Найти привлекательньий образ будущего - задача самоочевидная. Такая же, как эффективная молодежная политика, гармонизачия межначиональньх отношений, гарантия равньх возможностей или обеспечение сочиальной справедливости, (08.08.2017); 3) Решение вопроса сочиальной справедливости и большей вовлеченности широких слоев населения в проиесс экономического развития должно включать в себя борьбу с бедностью, но также и мерь по сокращению неравенства, причем не только по распределению доходов, но по возможностям развития всех категорий населения (равенство возможностей), (19.01.2017); 4) Принципь социальной справедливости являются определяющи- 
ми для развития России, для установления взаимопонимания и поддержки между властью и обществом, (20.02.2017); 5) Пришло время демонтировать мертвье стереотипь, которые удерживают нас в состоянии застоя и не позволяют национальному больиинству в законной и иивилизованной форме реализовать своё право на демократию, верность традиции и сочиальную справедливость, (28.04.2017); 6) Эксперты отметили необходимость формирования общего понятийного аппарата для выработки общей системь иенностей. В частности, было отмечено, что в употребление вошел цельии ряд слов-маркеров, которьле трактуются разньли аудиториями по-разному. В качестве примера Андрей Клемешев [...] привел понятие «рыночная экономика» [...]. То же самое касается выражения «социальная справедливость»-Клемешев пояснил, что одни понимают под этим «уравнитель», другие - «какие-то близкие стартовые позииии», (29.04.2017).

Следует отметить, что использование слова свобода также является достаточно распространенным и, в основном, выступает в контекстах связанных с лишением или ограничением свободы, со свободой слова и мнений, а также в качестве ссылки на западное соблюдение свобод, в том числе, иронического характера, ср. 1) На мой взгляд, обновленная редакиия образовательного стандарта никак не может ограничить творческую свободу учителя и школьного коллектива, (02.11.2017); 2) Очень важно, однако, не пойти по пути АНБ, ЦРУ и других американских спецслужб, чьи противозаконные методы слежки за собственньми и зарубежными гражданами стали известньи благодаря разоблачениям Эдварда Сноудена. Этот путь не способен обеспечить безопасность, но зато вполне может лииить нас свободы, (11.10.2017); 3) Союз журналистов России признал нападение на Фельгенгауэр атакой на свободу слова. Глава организаиии Всеволод Богданов предложил ужесточить наказание за подобные деяния, (23.10.2017); 4) Вместо того чтобь наладить конструктивньй диалог с властями автономии, иентральные испанские власти пошли путем репрессий и давления. Что, конечно, не вписьвается в декларируемые Европейским Союзом приниипь свободы мнений и права на референдум в любом вопросе, (25.09.2017); 5) Конеи политической романтики. Политолог Алексей Мартынов - о европейских свободах после референдума в Каталонии, (01.10.2017); 6) Представители «свободного западного мира»не раз были публично уличеньи практически во всех существующих формах интервенций в чужие дела, (29.09.2017). 
В свою очередь, на ряду со статьями, в которых подчеркивается значимость любви в жизни каждого человека, о чем свидетельствуют, данные ниже фрагменты, ср. 1) Творчество, вера, дружба, саморазвитие, любовь, создание семьи - хотелось бы, итобы всё это стало чертами нашей новой русской мечты, чтобы мь стремились быть лучше, стремились быть трезвыми, а не пьяныли Ваньками-дурачками (об идее Дня трезвости - И. В.), (11.09.2017); 2) Hem генов, отвечаюших за патриотизм или любовь $\boldsymbol{\kappa}$ людям. Эти качества воспитьваются семьей и школой, СМИ и интернетом, книгами и фильмами - всем, что окружает ребенка и подростка, (31.07.2017); 3) Как развить любовь и сострадание к ближнему, $\kappa$ семье, любимьлм и друзьям? Как сохранить вечные традииионные семейнье иенности, которыли всегда славилась и отличалась наша страна от других? Наш президент Владимир Путин искренне озаботился этой проблемой. И очень бы хотелось, чтобы тыссячи умных, образованньъх, по-настояшему духовных и нравственньх граждан нашей страньи последовали примеру российского лидера, (22.02.2017); 4) Ведь прививать детям любовь к итению лучше именно с помощью «живой» книги. Это первое, что нужно делать сегодня, (23.06.2017); 5) Любовь к природе России как национальная идея. Эколог Андрей Пешков - о том, как решаются главные проблемы охраны окружающей природной среды в Год экологии, (9.03.2017); существует ещё и другой контекст, в котором употребляется данная ценность, продиктован реалиями нынешней жизни, ср. 1) Деньги, займь, любовь, долги, ипотеки, вьнужденная необходимость зарабатьввать собственной красотой - это, $к$ сожалению, тот реальный мир, в котором мьл живем сегодня, (20.10.2017); 2) Огромного количества стрессов на работе можно избежать, если прививать сотрудникам любовь и приверженность своей компании, (10.10.2017); 3) Любовь к творчеству и желание создавать что-то новое лежат в основе успеха любого предприятия, (19.09.2017).

Последняя, рассматриваемая нами нравственно-духовная ценность - милосердие, встречается довольно редко, причем не только по сравнению с приведенными выше. В основном это контексты, где упоминается служба «Милосердие» или же это тексты воспевающие женские достоинства, публикуемые, зачастую по случаю 8 марта, ср. 1) Служба «Милосердие» проводит в рамках марафона акиию «Милосердие на бегу», в ходе которой надеется собрать 2 млн рублей на свои сочиальнье проекты помощи детям-инвалидам, бездомным и одиноким паииентам больнии; C 10-го на 5-е место переместилась служба помо- 
ши «Милосердие», увеличив за год объем привлеченных пожертвований в два раза, (04.05.2017); 2) Призвание женщины. Общественный деятель Екатерина Косточка - о роли женщинь, служении ближним и сестрах милосердия, (04.03.2017); 3) Ведь именно вы согреваете нас своей любовью, поддержкой и заботой. Именно вы в своем благородстве и милосердии выражаете истинную душу России, которую хочется оберегать и защищать; Когда я пишу портреть, то стараюсь увидеть в женщине самое лучшее и передать ее истинную красоту, где обычно всегда присутствуют и милосердие, и сердечность, и невероятное обаяние (статья к 8 марта - И. В.), (08.03.2017).

Анализируя собранный материал можно сделать вывод относительно тенденциозности большинства статей, нацеленных, главным образом, на экстраординарные события, сенсационность, что в последствии наносит ущерб объему освещения других тематик, сопутствующих продвижению позитивных ценностей, резкое падение которых замечается многими учеными. Многие из приведенных примеров свидетельствуют о том, что даже если такие ценности и появляются создается впечатление, что они зачастую используются в манипулятивных целях. Такая точка зрения имеет свои основания, поскольку, как подчеркивается, в настоящее время форма журналистики как элемента СМИ предполагает манипуляцию сознанием масс.

Парадокс заключается в том, что глобализация информационного пространства и обилие каналов связи лишают индивида личной нравственности. Стирается граница между тем, что хорошо и тем, что плохо, поэтому все сложнее становится однозначно оценить, происходящие в мире события как в моральном, так и эстетическом плане. Индивид теряет уверенность в том, что является морально одобряемым, а что порицаемым, так как те ориентиры, которые работали в условиях доинформационного общества стали недейственными. Вопрос состоит лишь в том вернется ли общество к традиционным идеалам или же предпочтение отдаст новым.

\section{Литература}

Bol'šoj psihologičeskij slovar', pod red. B. G. Meŝerâkova, V. P. Zinčenko, SanktPeterburg, 2007. [Большой психологический словарь, под ред. Б. Г. Мещерякова, В. П. Зинченко, Санкт-Петербург, 2007.]

D'âčkova M. A., 2007, Ponâtiâ cennost' $i$ duhovno-nravstvennye cennosti v pedagogike, «Sibirskij pedagogičeskij žurnal», № 12, Novosibirsk, [Дьячкова М. А., 
2007, Понятия ченность и духовно-нравственнье ченности в педагоги$\kappa e$, «Сибирский педагогический журнал», № 12, Новосибирск], [online], https://cyberleninka.ru/article/v/ponyatiya-tsennost-i-duhovno-nravstvenn ye-tsennosti-v-pedagogike, [14.08.2017].

Nikitina T. P., 2012, Sovremennyj čelovek v mire bez granic: nravstvennye cennosti $v$ informacionnom prostranstve, «Vestnik Permskogo universiteta: Filosofiâ. Psihologiâ. Sociologiâ», Vyp. 3, [Никитина Т. П., 2012, Современный человек в мире без границ: нравственнье ченности в инбормационном пространстве, «Вестник Пермского университета: Философия. Психология. Социология», Вып. 3], [online], https://cyberleninka.ru/article/v/ sovremennyy-chelovek-v-mire-bez-granits-nravstvennye-tsennosti-v-informa tsionnom-obschestve, [23.08.2017].

Prohorov E., 1988, Vvedenie v teoriû žurnalistiki, Moskva. [Прохоров E., 1988, Введение в теорию журналистики, Москва].

Tučkova V. V., 2012, Otraženie semejnyh cennostej v rossijskih SMI, «Izvestiâ» Rossijskogo gosudarstvennogo pedagogičeskogo universiteta im. A. I. Gercena, [Тучкова В. В., 2012, Отражение семейных ченностей в российских СМИ, «Известия» Российского государственного педагогического университета им. А.И. Герцена],[online], https://cyberleninka.ru/article/n/ otrazhenie-semeynyh-tsennostey-v-rossiyskih-smi, [01.09.2017].

\title{
SPIRITUAL AND MORAL VALUES IN THE STRUCTURE OF RUSSIAN MEDIA TEXTS \\ (ON THE EXAMPLE OF THE NEWSPAPER IZVESTIA)
}

\author{
S U M M A R Y
}

Key words: spiritual and moral values, globalization, crisis of values, media, society

The development of civilization and related transformation processes in society are affected the system of spiritual and moral values. As a result of intense and rapid changes in the end of the 20 th - beginning of the 21 st century connected with globalization, completely new values began to appear, those previously established ones were enriched and new spiritual and moral values were formed as a result of a combination of traditional and new values.

In connection with the growing processes of globalization, the issue of spiritual and moral values that are being spread in the media today has become very topical, especially considering that it is the mass media that play a very significant role in the struggle to preserve national and cultural identity. Therefore, the essence of our analysis constitutes of issues relating to the values that the authors of Russian media texts are guided by, the frequency of their mentioning according to the context. 